\title{
Newborn feeding practices at the time of discharge from hospital in NSW in 2007: a descriptive study
}

\author{
Lee K. Taylor ${ }^{\mathrm{A}, \mathrm{B}}$, Kim $\operatorname{Lim}^{\mathrm{A}}$ and \\ Sarah E. Neville \\ ${ }^{\mathrm{A} C e n t r e ~ f o r ~ E p i d e m i o l o g y ~ a n d ~ R e s e a r c h, ~ N S W ~ D e p a r t m e n t ~}$ \\ of Health \\ BCorresponding author.Email: ltayl@doh.health.nsw.gov.au
}

\begin{abstract}
Objectives: To describe the pattern of infant feeding at discharge from care after birth and the characteristics of mothers who are at risk of low rates of breastfeeding. Methods: Data were obtained from the NSW Midwives Data Collection for 2007. Information on infant feeding was obtained for babies who were alive at discharge from care after birth. Of 96030 births reported, 93505 (97.4\%) were eligible for analysis. A descriptive analysis of factors associated with variations in breastfeeding was carried out. Results: In $2007,80 \%$ of babies were fully breastfed, $7 \%$ were partially breastfed, and 13\% were not breastfed. Babies born to mothers with the following characteristics had relatively low rates of full breastfeeding: teenage mothers (69\%); Aboriginal mothers (64\%); mothers born in South-East Asia (71\%), North-East Asia (72\%) and Melanesia, Micronesia and Polynesia (74\%); mothers who commenced antenatal care later than 20 weeks gestation (74\%); mothers who smoked (67\%); mothers who received general anaesthetic during delivery (67\%); mothers who gave birth by caesarean section (76\%); mothers living in the most socially disadvantaged areas (73\%); mothers living in remote and very remote areas $(73 \%$ and $76 \%$ respectively); and mothers of preterm infants (70\%). Conclusion: There is a need to improve overall rates of breastfeeding initiation in NSW. Particular attention and support needs to be given to the groups of mothers identified in this study as having relatively low rates of full breastfeeding.
\end{abstract}

The benefits of breastfeeding for mothers and newborns are well documented. Benefits for the mother include reduction in postpartum bleeding, a contraceptive effect leading to increased spacing between pregnancies, and reduced risk of pre-menopausal breast cancer. For the infant, breastfeeding helps protect against diarrhoea, respiratory tract infections, otitis media and other infections. There is some evidence that breastfeeding is associated with reduced rates of allergies, obesity, diabetes, hypertension, cancer and Crohn's disease, and with improved intellectual and motor development. ${ }^{1}$

The National Health and Medical Research Council (NHMRC) recommends that infants are exclusively breastfed for the first 6 months of life and has established a target of at least $90 \%$ for initiation of breastfeeding in Australia. ${ }^{2}$ The NSW Health policy on breastfeeding ${ }^{3}$ identifies several strategies that are intended to improve initiation of breastfeeding. These include: implementation of the Baby Friendly Hospital Initiative across area health services; incorporating breastfeeding education and referral into routine antenatal care and other hospital and health services; and identifying and providing specific breastfeeding education and support interventions to women who are at risk of low rates of breastfeeding.

From 2007, the type of infant feeding on discharge from hospital has been reported for all infants born in New South Wales (NSW). The objectives of this study are to describe the pattern of breastfeeding practices at the time of discharge from care after birth and to describe the characteristics of mothers at risk of low rates of breastfeeding.

\section{Methods}

Data were obtained from the NSW Midwives Data Collection (MDC) for 2007. The MDC is a populationbased surveillance system covering all births in NSW public and private hospitals, as well as home births. It encompasses all live births and stillbirths of at least 20 weeks gestation or at least $400 \mathrm{~g}$ birth weight. Births in NSW are reported to the NSW Department of Health under the NSW Public Health Act 1991.

From 2007, the MDC has collected information on infant feeding at the time of discharge from hospital 
(or discharge from care for home births) for all infants born in NSW. Infant feeding is reported via three tick-box categories: breastfeeding, expressed breastmilk and infant formula. More than one type of feeding may be reported by ticking multiple boxes. Infant feeding was classified into three categories: full breastfeeding, which included babies who were reported to be breastfed or to be receiving expressed breastmilk; any breastfeeding, which included babies who were reported to be receiving breastmilk and infant formula; and no breastfeeding.

Information on breastfeeding was obtained from the MDC for babies who were born in 2007 and who were alive at the time of discharge from care - records of stillborn babies, babies who died in the hospital of birth, and babies for whom information on breastfeeding was not stated were excluded. Of the 96030 births reported to the MDC in 2007, 93505 (97.4\%) were eligible for analysis. Of the 2525 excluded birth records, 1465 did not contain information about breastfeeding.

In this article, the term Aboriginal is used to encompass both Aboriginal and Torres Strait Islander mothers. Country of birth groups were created from categories defined in the Standard Australian Classification of Countries. ${ }^{4}$ The enhanced Accessibility/Remoteness Index of Australia (ARIA +$)^{5}$ was used to measure remoteness. The ARIA + value is based on road distance to a 'service centre'. Births were classified into five categories of remoteness, determined by the ARIA + score of their Statistical Local Area (SLA) of residence in NSW, ranging from major cities to very remote areas. Socioeconomic groups were constructed using the Index of Relative Socioeconomic Disadvantage (IRSD), which is one of the Socioeconomic Indices (SEIFA) produced by the Australian Bureau of Statistics (ABS). ${ }^{6}$ IRSD scores based on the 2006 Census were assigned to SLAs in NSW. The NSW population was divided into five groups based on the IRSD scores of their SLA of residence. Births were allocated to one of five groups from the lowest quintile (most disadvantaged) to the highest quintile (least disadvantaged). Descriptive analyses were carried out using SAS version 9.1.3.7 Analgesia administered during labour and/or delivery was classified into five mutually exclusive groups. These groups were: non-pharmacological only (including no pain relief); gas (nitrous oxide) with no other pharmacological analgesia; narcotics (usually pethidine), with or without gas; epidural (including epidural, caudal, spinal and combined methods), with or without narcotics or gas; and general anaesthetic, with or without epidural, narcotics or gas.

\section{Results}

On discharge from hospital in $2007,80 \%$ of babies were fully breastfed, $6.5 \%$ were partially breastfed and $13.2 \%$ were not breastfed.
Table 1 shows that rates of full breastfeeding were lower among babies born to the following population groups:

- mothers aged less than 20 years - the lowest rates of full breastfeeding were among teenage mothers $(69 \%)$, who also had the highest rate of no breastfeeding (28\%). Rates of full breastfeeding rose with increasing maternal age to a high of $82 \%$ among mothers aged 30-34 years and then declined slightly to $79 \%$ among mothers aged 40 years and over.

- Aboriginal mothers compared to non-Aboriginal mothers $-64 \%$ of Aboriginal mothers fed their babies fully with breastmilk compared to $81 \%$ of nonAboriginal mothers. The proportion of babies born to Aboriginal mothers who were not breastfed was more than twice that of babies born to non-Aboriginal mothers (31\% versus 13\%).

- mothers born in South-East Asia, North-East Asia and Melanesia, Micronesia and Polynesia - less than 75\% of babies of mothers born in South-East Asia, NorthEast Asia and Melanesia, Micronesia and Polynesia were fully breastfed compared to $81 \%$ of mothers born in English-speaking countries and $88 \%$ of babies of mothers born in Eastern Europe, Russia and Central Asian and Baltic States.

- mothers who commenced antenatal care later (greater than 20 weeks gestation) rather than earlier $-74 \%$ of babies born to mothers who commenced antenatal care after 20 weeks gestation were fully breastfed, compared with $81 \%$ of mothers who commenced antenatal care at less than 20 weeks gestation.

- mothers who smoked during pregnancy $-82 \%$ of mothers who did not smoke during pregnancy fully breastfed their babies, compared with $67 \%$ of mothers who did smoke.

- mothers who received general anaesthetic during delivery $-67 \%$ of babies born to mothers who received a general anaesthetic during delivery were fully breastfed, lower than the $81 \%$ of babies born to mothers who received other forms of analgesia during labour or delivery, and $84 \%$ of babies born to mothers who received non-pharmacological pain relief.

- mothers who gave birth by vaginal breech delivery or by caesarean section - the lowest rates of full breastfeeding were among mothers who gave birth by vaginal breech delivery $(71 \%)$ and by caesarean section $(76 \%)$.

- mothers living in remote and very remote areas - of mothers living in remote and very remote areas, 74\% fully breastfed their babies, compared to over $80 \%$ of mothers in more accessible areas.

- mothers living in relatively socially disadvantaged areas - there was a trend of increasing rates of full breastfeeding with increasing socioeconomic status. 
Table 1. Maternal and infant factors associated with infant feeding practices at discharge from care after birth, NSW, 2007

\begin{tabular}{|c|c|c|c|c|c|c|c|c|}
\hline & \multicolumn{2}{|c|}{ Full breastfeeding } & \multicolumn{2}{|c|}{ Any breastfeeding } & \multicolumn{2}{|c|}{ No breastfeeding } & & \\
\hline & $n$ & $\%$ & $n$ & $\%$ & $n$ & $\%$ & $n$ & $\%$ \\
\hline Maternal age (years) & & & & & & & & \\
\hline $12-19$ & 2227 & 68.5 & 118 & 3.6 & 905 & 27.8 & 3250 & 100 \\
\hline $20-24$ & 9865 & 76.6 & 669 & 5.2 & 2350 & 18.2 & 12884 & 100 \\
\hline $25-29$ & 20122 & 80.5 & 1569 & 6.3 & 3296 & 13.2 & 24987 & 100 \\
\hline $30-34$ & 25402 & 82.2 & 2055 & 6.7 & 3428 & 11.1 & 30885 & 100 \\
\hline $35-39$ & 14697 & 81.8 & 1369 & 7.6 & 1899 & 10.6 & 17965 & 100 \\
\hline $40+$ & 2765 & 78.6 & 331 & 9.4 & 422 & 12 & 3518 & 100 \\
\hline Not stated & 14 & 87.5 & 2 & 12.5 & 0 & 0 & 16 & 100 \\
\hline TOTAL & 75092 & 80.3 & 6113 & 6.5 & 12300 & 13.2 & 93505 & 100 \\
\hline Maternal Aboriginality & & & & & & & & \\
\hline Aboriginal or TSI & 1778 & 64.4 & 128 & 4.6 & 857 & 31 & 2763 & 100 \\
\hline Non-Aboriginal & 73175 & 80.8 & 5968 & 6.6 & 11419 & 12.6 & 90562 & 100 \\
\hline Not stated & 139 & 77.2 & 17 & 9.4 & 24 & 13.3 & 180 & 100 \\
\hline TOTAL & 75092 & 80.3 & 6113 & 6.5 & 12300 & 13.2 & 93505 & 100 \\
\hline Maternal country of birth & & & & & & & & \\
\hline English speaking & 58603 & 81.1 & 3213 & 4.4 & 10454 & 14.5 & 72270 & 100 \\
\hline Central \& South America & 669 & 83.8 & 79 & 9.9 & 50 & 6.3 & 798 & 100 \\
\hline Melanesia, Micronesia \& Polynesia & 1106 & 73.6 & 179 & 11.9 & 217 & 14.4 & 1502 & 100 \\
\hline Southern Europe & 653 & 77.6 & 78 & 9.3 & 110 & 13.1 & 841 & 100 \\
\hline Western \& Northern Europe & 677 & 88 & 43 & 5.6 & 49 & 6.4 & 769 & 100 \\
\hline Eastern Europe, Russia, & & & & & & & & \\
\hline Central Asian \& Baltic States & 611 & 88.3 & 46 & 6.6 & 35 & 5.1 & 692 & 100 \\
\hline Middle East \& Africa & 3489 & 81.5 & 430 & 10.0 & 363 & 8.5 & 4282 & 100 \\
\hline South-East Asia & 3578 & 70.5 & 917 & 18.1 & 577 & 11.4 & 5072 & 100 \\
\hline North-East Asia & 2856 & 72.4 & 768 & 19.5 & 323 & 8.2 & 3947 & 100 \\
\hline Southern Asia & 2696 & 85.8 & 347 & 11 & 101 & 3.2 & 3144 & 100 \\
\hline Other - not stated & 154 & 81.9 & 13 & 6.9 & 21 & 11.2 & 188 & 100 \\
\hline TOTAL & 75092 & 80.3 & 6113 & 6.5 & 12300 & 13.2 & 93505 & 100 \\
\hline $\begin{array}{l}\text { Duration of pregnancy at first anten } \\
\text { visit (weeks) }\end{array}$ & & & & & & & & \\
\hline $0-19$ & 68940 & 81.1 & 5419 & 6.4 & 10605 & 12.5 & 84964 & 100 \\
\hline $20+$ & 4911 & 73.5 & 522 & 7.8 & 1248 & 18.7 & 6681 & 100 \\
\hline Not stated & 1241 & 66.7 & 172 & 9.2 & 447 & 24 & 1860 & 100 \\
\hline TOTAL & 75092 & 80.3 & 6113 & 6.5 & 12300 & 13.2 & 93505 & 100 \\
\hline Smoking in pregnancy & & & & & & & & \\
\hline No & 67026 & 82.3 & 5527 & 6.8 & 8853 & 10.9 & 81406 & 100 \\
\hline Yes & 7805 & 66.7 & 559 & 4.8 & 3344 & 28.6 & 11708 & 100 \\
\hline Not stated & 261 & 66.8 & 27 & 6.9 & 103 & 26.3 & 391 & 100 \\
\hline TOTAL & 75092 & 80.3 & 6113 & 6.5 & 12300 & 13.2 & 93505 & 100 \\
\hline Analgesia & & & & & & & & \\
\hline Non-pharmacological & 14609 & 83.8 & 796 & 4.6 & 2019 & 11.6 & 17424 & 100 \\
\hline Gas & 17104 & 83 & 1037 & 5 & 2462 & 11.9 & 20603 & 100 \\
\hline Narcotic & 8264 & 78.8 & 608 & 5.8 & 1611 & 15.4 & 10483 & 100 \\
\hline Epidural & 32697 & 78.9 & 3296 & 8 & 5422 & 13.1 & 41415 & 100 \\
\hline General anaesthetic & 2398 & 67.4 & 376 & 10.6 & 785 & 22.1 & 3559 & 100 \\
\hline Not stated & 20 & 95.2 & 0 & 0 & 1 & 4.8 & 21 & 100 \\
\hline TOTAL & 75092 & 80.3 & 6113 & 6.5 & 12300 & 13.2 & 93505 & 100 \\
\hline Type of birth & & & & & & & & \\
\hline Normal vaginal & 45696 & 82.3 & 2794 & 5 & 7022 & 12.6 & 55512 & 100 \\
\hline Forceps & 2641 & 81.3 & 296 & 9.1 & 312 & 9.6 & 3249 & 100 \\
\hline Vacuum extraction & 5541 & 82.1 & 523 & 7.8 & 682 & 10.1 & 6746 & 100 \\
\hline Vaginal breech & 225 & 71 & 39 & 12.3 & 53 & 16.7 & 317 & 100 \\
\hline Caesarean section & 20923 & 75.8 & 2460 & 8.9 & 4228 & 15.3 & 27611 & 100 \\
\hline Not stated & 66 & 94.3 & 1 & 1.4 & 3 & 4.3 & 70 & 100 \\
\hline TOTAL & 75092 & 80.3 & 6113 & 6.5 & 12300 & 13.2 & 93505 & 100 \\
\hline Plurality & & & & & & & & \\
\hline Singleton & 73591 & 80.9 & 5619 & 6.2 & 11703 & 12.9 & 90913 & 100 \\
\hline Twin & 1468 & 57.8 & 482 & 19 & 591 & 23.3 & 2541 & 100 \\
\hline Triplet & 33 & 64.7 & 12 & 23.5 & 6 & 11.8 & 51 & 100 \\
\hline TOTAL & 75092 & 80.3 & 6113 & 6.5 & 12300 & 13.2 & 93505 & 100 \\
\hline Gestational age (weeks) & & & & & & & & \\
\hline$<28$ & 103 & 64.8 & 15 & 9.4 & 41 & 25.8 & 159 & 100 \\
\hline $28-31$ & 314 & 68.6 & 61 & 13.3 & 83 & 18.1 & 458 & 100 \\
\hline $32-36$ & 3652 & 70.1 & 569 & 10.9 & 987 & 19 & 5208 & 100 \\
\hline $37-41$ & 70249 & 81 & 5420 & 6.2 & 11095 & 12.8 & 86764 & 100 \\
\hline $42+$ & 758 & 85 & 44 & 4.9 & 90 & 10.1 & 892 & 100 \\
\hline Not stated & 16 & 66.7 & 4 & 16.7 & 4 & 16.7 & 24 & 100 \\
\hline TOTAL & 75092 & 80.3 & 6113 & 6.5 & 12300 & 13.2 & 93505 & 100 \\
\hline ARIA* category & & & & & & & & \\
\hline Major Cities & 48716 & 79.4 & 4985 & 8.1 & 7670 & 12.5 & 61371 & 100 \\
\hline Inner Regional & 18345 & 82.1 & 777 & 3.5 & 3220 & 14.4 & 22342 & 100 \\
\hline Outer Regional & 6051 & 81.8 & 241 & 3.3 & 1102 & 14.9 & 7394 & 100 \\
\hline Remote & 480 & 73.3 & 32 & 4.9 & 143 & 21.8 & 655 & 100 \\
\hline Very Remote & 153 & 75.7 & 5 & 2.5 & 44 & 21.8 & 202 & 100 \\
\hline TOTAL & 73745 & 80.2 & 6040 & 6.6 & 12179 & 13.2 & 91964 & 100 \\
\hline Index of Relative Socioeconomic Dis & & & & & & & & \\
\hline 1st quintile (most disadvantaged) & 14973 & 72.7 & 1921 & 9.3 & 3699 & 18 & 20593 & 100 \\
\hline 2nd quintile & 13867 & 80.2 & 734 & 4.2 & 2693 & 15.6 & 17294 & 100 \\
\hline 3rd quintile & 13702 & 80.7 & 919 & 5.4 & 2360 & 13.9 & 16981 & 100 \\
\hline 4th quintile & 14909 & 80.7 & 1362 & 7.4 & 2194 & 11.9 & 18465 & 100 \\
\hline 5th quintile (least disadvantaged) & 16294 & 87.5 & 1104 & 5.9 & 1233 & 6.6 & 18631 & 100 \\
\hline TOTAL & 73745 & 80.2 & 6040 & 6.6 & 12179 & 13.2 & 91964 & 100 \\
\hline
\end{tabular}


Rates of full breastfeeding were also lower in babies born of multiple pregnancies (twins and triplets) compared to singleton babies, and babies born prematurely compared to babies born at term.

\section{Discussion}

Information on breastfeeding at discharge from care after birth was available for the first time on a population basis in NSW in 2007. While some babies may be fully breastfed immediately after birth, and not fully breastfed by the time they are discharged from care, it is likely that the NHMRC target of at least $90 \%$ for initiation of breastfeeding is currently not being met in NSW.

The study identified groups of mothers who have relatively low rates of full feeding with breastmilk: teenage mothers; Aboriginal mothers; mothers who smoke; mothers born in South-east Asia, North-east Asia and Melanesia, Micronesia and Polynesia; mothers who gave birth by vaginal breech delivery or by caesarean section; mothers who received a general anaesthetic during delivery; mothers living in rural and remote areas; mothers living in socially disadvantaged areas; mothers of twins and triplets; and mothers of preterm infants. However, there is little population-based information in Australia to allow comparison.

This pattern was also found in a sample of children born between 2003 and 2004 and followed up as part of the Longitudinal Study of Australian Children (LSAC). ${ }^{8}$ The LSAC measured breastfeeding initiation rather than breastfeeding at hospital discharge and therefore found higher rates of breastfeeding initiation than our study: initiation was lower for infants of 35-36 weeks' gestation $(88.2 \%)$ than $37-39$ weeks' gestation $(92.0 \%)$ and $\geqslant 40$ weeks' gestation (93.9\%). Twins and triplets, and babies born by vaginal breech delivery, are more likely to be premature - the relatively lower rate of full breastfeeding among premature infants is likely to explain at least some of the lower rate of breastfeeding in these groups of infants.

We found that rates of full breastfeeding were lower among mothers who received general anaesthesia during delivery compared to other forms of analgesia or no analgesia. A similar pattern was found by Torvaldsen et al in a cohort study of mothers from the Australian Capital Territory who gave birth in 1997, although they found $93 \%$ of mothers either fully or partially breastfed their babies in the first week postpartum, a substantially higher percentage than in this study. ${ }^{9}$

In an examination of data from the Australian National Health Surveys carried out by the ABS in 1995, 2001 and 2004-05, Amir et al found that social disadvantage was consistently associated with lower rates of initiation of breastfeeding. ${ }^{10}$ They also found an increasing difference between the highest and lowest socioeconomic groups over time, with infants in higher socioeconomic groups more likely to be breastfed in 2004-05 than previously. While we do not have data from past years for comparison, we found a substantial difference $(15 \%)$ in rates of full breastfeeding between the lowest and highest socioeconomic groups.

A limitation of this study is that the validity of reporting infant feeding practices on the MDC is not known, although previous validation studies of the MDC have found the validity of information collected on events occurring during birth and the immediate postpartum period are generally well reported. ${ }^{11,12}$ This study was restricted to an examination of maternal and infant factors for which information was available on the MDC. Elsewhere, other factors have been found to be associated with initiation of breastfeeding. In the LSAC, lower rates of initiation of breastfeeding were found among overweight and obese mothers compared to mothers of normal weight. ${ }^{13}$ In a cohort study of mothers giving birth in four hospitals in Western Australia and Queensland, breastfeeding at hospital discharge was found to be most strongly associated with perceived paternal support of breastfeeding, followed by the infant feeding decision being made before pregnancy and the baby having a normal (as opposed to low) birth weight. ${ }^{14}$ Information on socioeconomic status was limited to ecological measures of SEIFA and ARIA in our study, and information on health service activities promoted as part of the joint WHO-UNICEF Baby Friendly Hospital Initiative, such as rooming-in practice and encouraging breastfeeding on demand, are not collected as part of the MDC. Furthermore, intention to breastfeed is not reported on the MDC and it may be that some mothers have already made a decision not to breastfeed prior to the birth. This study is descriptive and further work is needed to explore how factors associated with breastfeeding interact and which factors are more strongly associated with breastfeeding once the other factors are taken into account.

Despite these limitations, this study provides information on factors that can be used in the clinical setting to help identify mothers who are at risk of not breastfeeding.

\section{Conclusion}

There is a need to improve rates of initiation of breastfeeding in NSW. While initiation rates need to be improved in general, particular attention should be given to the population groups identified by this study.

\section{References}

1. León-Cava N, Lutter C, Ross J, Martin L. Quantifying the benefits of breastfeeding: a summary of the evidence. Washington DC: Pan American Health Organization; 2002. 
2. National Health and Medical Research Council. Dietary guidelines for children and adolescents in Australia incorporating the infant feeding guidelines for health workers. Canberra: AusInfo; 2003.

3. NSW Department of Health. Breastfeeding in NSW: Promotion, Protection and Support. Policy Directive 2006/12. Available from: www.health.nsw.gov.au/policies/ pd/2006/PD2006_012.html (Cited 30 September 2009.)

4. Australian Bureau of Statistics. Standard Australian Classification of Countries (SACC), Australia. 2nd ed. Cat. No. 1269.0. ABS: Canberra; 2008.

5. GISCA. About ARIA + (Accessibility/Remoteness Index of Australia). Available from: http://www.gisca.adelaide.edu.au/ products_services/ariav2_about.html

6. Australian Bureau of Statistics. Information paper: 2006 Socioeconomic indexes for areas. Cat. No. 2039.0. ABS: Canberra; 2008.

7. SAS Institute Inc., Cary, NC, USA.

8. Donath SM, Amir LH. Effect of gestation on initiation and duration of breastfeeding. Arch Dis Child Fetal Neonatal Ed 2008; 93(6): F448-50. doi:10.1136/adc.2007.133215
9. Torvaldsen S, Roberts CL, Simpson JM, Thompson JF, Ellwood DA. Intrapartum epidural analgesia and breastfeeding: a prospective cohort study. Int Breastfeed $J$ 2006; 1: 24. doi:10.1186/1746-4358-1-24

10. Amir LH, Donath SM. Socioeconomic status and rates of breastfeeding in Australia: evidence from three recent national health surveys. Med J Aust 2008; 189(5): 254-6.

11. Pym M, Taylor L. Validation Study of the New South Wales Midwives Data Collection 1990. N S W Public Health Bull Supplement. Sydney: NSW Health Department; 1993.

12. Taylor L, Pym M, Bajuk B, Sutton L, Travis S, Banks C. NSW Mothers and Babies 1998. N S W Public Health Bull Supplement. Sydney: NSW Health Department; 2000.

13. Donath SM, Amir L. Maternal obesity and initiation and duration of breastfeeding: data from the longitudinal study of Australian children. Matern Child Nutr 2008; 4(3): 163-70. doi:10.1111/j.1740-8709.2008.00134.x

14. Scott J, Landers M, Hughes R, Binns C. Factors associated with breastfeeding at discharge and duration of breastfeeding. J Paediatr Child Health 2001; 37: 254-61. doi:10.1046/ j.1440-1754.2001.00646.x 